Published in final edited form as:

Curr Gene Ther. 2007 April ; 7(2): 79-88.

\title{
Gene Therapy for Type I Glycogen Storage Diseases
}

\author{
Janice Y. Chou ${ }^{1}$ and Brian C. Mansfield ${ }^{1,2}$ \\ 1 Section on Cellular Differentiation, Heritable Disorders Branch, National Institute of Child Health and \\ Human Development, National Institutes of Health, Bethesda, MD 20892
}

2Correlogic Systems, Inc., Rockville, MD 20850

\section{Abstract}

The type I glycogen storage diseases (GSD-I) are a group of related diseases caused by a deficiency in the glucose-6-phosphatase- $\alpha$ (G6Pase- $\alpha$ ) system, a key enzyme complex that is essential for the maintenance of blood glucose homeostasis between meals. The complex consists of a glucose-6phosphate transporter (G6PT) that translocates glucose-6-phosphate from the cytoplasm into the lumen of the endoplasmic reticulum, and a G6Pase- $\alpha$ catalytic unit that hydrolyses the glucose-6phosphate into glucose and phosphate. A deficiency in G6Pase- $\alpha$ causes GSD type Ia (GSD-Ia) and a deficiency in G6PT causes GSD type Ib (GSD-Ib). Both GSD-Ia and GSD-Ib patients manifest a disturbed glucose homeostasis, while GSD-Ib patients also suffer symptoms of neutropenia and myeloid dysfunctions. G6Pase- $\alpha$ and G6PT are both hydrophobic endoplasmic reticulum-associated transmembrane proteins that can not expressed in soluble active forms. Therefore protein replacement therapy of GSD-I is not an option. Animal models of GSD-Ia and GSD-Ib that mimic the human disorders are available. Both adenovirus- and adeno-associated virus (AAV)-mediated gene therapies have been evaluated for GSD-Ia in these model systems. While adenoviral therapy produces only short term corrections and only impacts liver expression of the gene, AAV-mediated therapy delivers the transgene to both the liver and kidney, achieving longer term correction of the GSD-Ia disorder, although there are substantial differences in efficacy depending on the AAV serotype used. Gene therapy for GSD-Ib in the animal model is still in its infancy, although an adenoviral construct has improved the metabolic profile and myeloid function. Taken together further refinements in gene therapy may hold long term benefits for the treatment of type I GSD disorders.

\section{Introduction}

The type I glycogen storage diseases, GSD-I, are a group of autosomal recessive disorders caused by a deficiency in the glucose-6-phosphatase- $\alpha$ (G6Pase- $\alpha$ ) complex (Fig. 1) [Chen 2001; Chou et al., 2002]. Currently, two enzyme activities, embedded in the endoplasmic reticulum (ER) membrane are implicated in GSD-I. One activity is a glucose-6-phosphate transporter (G6PT) that translocates glucose-6-phosphate (G6P) from the cytoplasm into the lumen of the ER. The second activity is a glucose-6-phosphatase catalytic unit (G6Pase, also known as G6PC) that hydrolyses G6P into glucose and phosphate [Chen 2001; Chou et al., 2002]. Early literature only recognized a single G6Pase activity. More recently a second activity was identified [Guionie et al., 2003;Shieh et al., 2003;Ghosh et al., 2004]. The original G6Pase is now more specifically identified as G6Pase- $\alpha$, while the more recent activity is called G6Pase- $\beta$ [Shieh et al., 2003; Ghosh et al., 2004]. Blood glucose homeostasis between meals is maintained by the G6Pase- $\alpha$-G6PT complex. A deficiency of G6Pase- $\alpha$ causes GSD type Ia (GSD-Ia, MIM232200) and a deficiency in G6PT causes GSD type Ib (GSD-Ib, MIM232220).

Correspondence should be addressed to: Janice Y. Chou, Building 10, Room 9D42, NIH, Bethesda, MD 20892-1830, Tel: 301-496-1094, Fax: 301-402-6035, Email: chouja@mail.nih.gov. 
The expression of G6Pase- $\alpha$ is tissue restricted, the predominant sites of expression being the liver, kidney, and intestine [Nordlie and Sukalski 1985;Pan et al., 1998b]. In contrast, G6PT is expressed ubiquitously [Lin et al., 1998]. Both GSD-Ia and GSD-Ib patients fail to hydrolyze G6P to glucose and manifest a phenotype of a disturbed glucose homeostasis. The hallmark of all GSD-I is hypoglycemia following a short fast [Chen 2001; Chou et al., 2002]. This loss of glucose homeostasis leads to the accumulation of elevated levels of G6P in the cytoplasm. This in turn stimulates the alternative metabolic pathways involving G6P (Fig. 2) which lead to the hypertriglyceridemia, hypercholesterolemia, hyperuricemia, and lactic acidemia that also characterize the clinical pathophysiology of all GSD-I. The elevated levels of G6P also lead to excessive accumulation of glycogen in the liver and kidney, which promotes progressive hepatomegaly and nephromegaly. Additional accumulation of fat droplets in the liver also contributes significantly to the hepatomegaly. Unlike the GSD-Ia patients, GSD-Ib patients manifest additional symptoms of neutropenia and myeloid dysfunctions [Beaudet et al., 1980;Gitzelmann and Bosshard 1993; Visser et al., 2002;Chou and Mansfield 2003] that are not obviously related to metabolism in the gluconeogenic tissues. In examining the potential roles of G6PT outside of the gluconeogenic tissues, a recent bone marrow transplantation study established that G6PT expression in the bone marrow is required for normal neutrophil and myeloid functions [Kim et al., 2006].

There is no cure for GSD-Ia or GSD-Ib and both are fatal within the first two decades of life if not treated [Chen 2001; Chou et al., 2002]. The current treatment for both GSD-Ia and GSD$\mathrm{Ib}$ is a dietary therapy augmented by various conventional drugs. Infants typically receive nocturnal nasogastric infusion of glucose to avoid hypoglycemia [Greene et al., 1976]. Older patients eat uncooked cornstarch, which acts as a slow release carbohydrate, to prolong the length of euglycemia between meals [Chen et al., 1984]. GSD-Ib patients also receive granulocyte colony stimulating factor (G-CSF) therapy to restore myeloid functions [Schroten et al., 1991; Roe et al., 1992]. While these therapies are sufficiently successful to enable patients to attain near normal growth and pubertal development, the underlying pathological process remains uncorrected and patients continue to suffer from hyperlipidemia, hyperuricemia, hypercalciuria, hypocitraturia, and lactic acidemia [Chen 2001; Chou et al., 2002]. As a result, long-term complications such as short stature, osteoporosis, gout, renal disease, pulmonary hypertension and hepatic adenomas, that may undergo malignant transformation, still persist in GSD-I patients and become increasingly significant in older patients. In addition to these conditions, GSD-Ib patients are at a significantly higher risk of developing inflammatory bowl disease [Roe et al., 1986; Visser et al., 2000], while G-CSF therapy also increases the risk of splenomegaly [Calderwood et al., 2001]. A significant practical problem with this therapeutic approach is that despite the benefits of dietary therapy, its efficacy is frequently limited due to poor compliance.

Alternative therapeutic approaches to the GSD-I disorders are required. Both G6Pase- $\alpha$ and G6PT are hydrophobic ER-associated transmembrane proteins [Pan et al., 1998a;1998c; 1999] that must not only embed within the ER membrane in the correct conformation, but also couple with each other functionally, to hydrolyze G6P to glucose [Lei et al., 1996; Hiraiwa et al., 1999]. Attempts to express the proteins in a way that would allow their isolation in an active soluble form have been unsuccessful due to their hydrophobicity, ruling out protein replacement therapy as a current treatment option. An alternative therapeutic approach is gene therapy. Animal disease models of GSD-Ia [Lei et al., 1996; Kishnani et al., 1997;2001] and GSD-Ib [Chen et al., 2003] that closely mimic the human disorders are available and have been used to develop somatic gene therapies and are showing promise as more efficacious treatments for GSD-I. 


\section{GSD-la}

G6Pase- $\alpha$ deficiency (GSD-Ia) is the most prevalent form of GSD-I, representing over $80 \%$ of GSD-I cases [Chen 2001; Chou et al., 2002]. The disease is caused by a deficiency in the G6Pase- $\alpha$ catalytic unit that hydrolyses G6P into glucose and phosphate in the terminal step of gluconeogenesis and glycogenolysis (Fig. 2). Both human [Lei et al., 1993] and mouse [Shelly et al., 1993] G6Pase- $\alpha$ are encoded by single copy genes, spanning 10-12 kb of chromosomal DNA, and composed of 5 exons. In the human, the gene maps to chromosome 17q21 [Lei et al., 1994] and in the mouse it maps to chromosome 11. In both organisms, expression is limited primarily to the liver, kidney cortex, and intestine [Nordlie and Sukalski 1985; Pan et al., 1998c]. Human and mouse G6Pase- $\alpha$ proteins are highly hydrophobic, 357 amino acid glycoproteins, sharing $88 \%$ sequence identity, which includes the conserved amino acid residues participating in catalysis and the potential glycosylation sites [reviewed in Chou and Mansfield 1999]. In human G6Pase- $\alpha \mathrm{Asp}^{96}$ was shown to be the acceptor for oligosaccharide chains [Pan et al., 1998c].

Human G6Pase- $\alpha$ is anchored in the ER by 9-transmembrane helices with the amino-terminus in the ER lumen and the carboxyl-terminus in the cytoplasm [Pan et al., 1998a;1998c] (Fig. 1). The amino acids comprising the catalytic center of G6Pase- $\alpha$ include $\mathrm{Lys}^{76}, \mathrm{Arg}^{83}$, His ${ }^{119}$, Arg ${ }^{170}$, and His ${ }^{176}$. His ${ }^{176}$ in G6Pase- $\alpha$ is the nucleophile that covalently bound the phosphate moiety forming the phosphohistidine-G6Pase- $\alpha$ intermediate during catalysis [Ghosh et al., 2002]. Of these residues, all but Lys ${ }^{76}$ (in helix-2), are predicted to lie on the luminal side of the ER (Fig. 1), confirming the view that the active site of G6Pase- $\alpha$ is not accessible from the cytoplasm. Therefore, G6P hydrolysis is dependent upon transport of the cytoplasmic G6P across the ER membrane by G6PT [Chou et al., 2002; Chou and Mansfield 2003]. To be functional, G6Pase- $\alpha$ must couple with the G6PT [Lei et al., 1996; Hiraiwa et al., 1999].

GSD-Ia patients manifest a phenotype of disturbed glucose homeostasis, characterized by growth retardation, hypoglycemia, hepatomegaly, nephromegaly, hypertriglyceridemia, hypercholesterolemia, hyperuricemia, and lactic acidemia. Long-term complications include osteoporosis, gout, renal disease, pulmonary hypertension, and hepatic adenomas that may undergo malignant transformation. Renal transplantation in GSD-Ia patients normalized kidney function but failed to correct the metabolic abnormalities [Emmett and Narins, 1978; Chen and Scheinman, 1991; Gossmann et al., 2001], consistent with the primary role of the liver in glucose homeostasis. Presently, in patients who fail to respond sufficiently to dietary therapy, or who exhibit multiple liver adenomas and risk of malignant transformation, orthotopic liver transplantation is advocated [reviewed in Matern et al., 1999; Labrune, 2002]. In patients who present with, or have an impending, renal failure, a combined liver and kidney transplantation may be considered [Matern et al., 1999]. Liver transplantation appears to correct metabolic abnormalities in the short term, but there is insufficient experience yet to conclude whether it will be effective in the long term, especially in preventing the development of slowly progressing renal disease [Matern et al., 1999; Labrune, 2002]. In addition, liver transplantation is a highly invasive procedure, requires matched donors, carries complications inherent to long-term immunosuppressive therapy, and the risk of rejection. Therefore alternative treatment strategies are required.

\section{Gene therapy for GSD-la}

There are mouse [Lei et al., 1996] and dog [Kishnani et al., 1997; 2001] models of GSD-Ia. Both animal models are being used to further our understanding of the biology and pathophysiology of GSD-Ia and to develop novel therapies for this disorder. The GSD-Ia $\left(\right.$ G6Pase- $\left.\alpha^{-/-}\right)$mice [Lei et al., 1996] were generated by gene targeting and manifest all of the 
symptoms of human GSD-Ia - hypoglycemia, growth retardation, hepatomegaly, nephromegaly, hyperlipidemia, and hyperuricemia - with the exception of hyperlactacidemia. The originally identified GSD-Ia dog is a Maltese breed carrying a natural G450C/M121I G6Pase- $\alpha$ mutation. Transient expression assays show this mutation retains only $6.6 \%$ of wildtype activity [Kishnani et al., 1997]. More recently, because the Maltese breed is small in size, exhibits low survival rate of newborns, and has a small litter size, a new dog model was established by crossbreeding the carrier Maltase dog with Beagles [Kishnani et al., 2001]. Both canine models manifest all the typical symptoms of the human disorder, including hyperlactacidemia [Kishnani et al., 1997; 2001], but is less readily manipulable than the mouse model. The phenotypic similarity between the GSD-Ia mice carrying a null mutation and the GSD-Ia dog carrying 6.6\% normal hepatic activity indicates that to correct the GSD-Ia disorder, more than $7 \%$ of normal activity must be restored in the liver.

In 2000, Zingone et al. used G6Pase- $\alpha^{-/-}$mice to evaluate the feasibility of gene replacement therapy for GSD-Ia using an adenoviral (Ad) vector carrying murine G6Pase- $\alpha$ (Ad-mG6Pase$\alpha$ ) under the control of the constitutive RSV promoter. A single intravenous infusion of $2 \times$ $10^{9}$ plaque forming unit (PFU) of Ad-mG6Pase- $\alpha$ into the G6Pase- $\alpha^{-/-}$mice at 2 weeks of age restored $19 \%$ of normal hepatic G6Pase- $\alpha$ activity, improved survival and growth of GSD-Ia mice, and transiently corrected the metabolic abnormalities manifested by these mice.

However, the benefits were short-lived because of the rapid loss of the vector-mediated gene [Benihoud et al., 1999; Wilson 2001].

To achieve long-term correction of the GSD-Ia disorder, more stable transgene expression is required. Recombinant adeno-associated virus (rAAV) vectors are particularly attractive in this respect. The rAAV vectors have generally proven to transduce non-dividing cells efficiently, leading to long-term expression of the introduced recombinant gene [Carter and Samulski 2000; Tenenbaum et al., 2003; McCarty et al., 2004; Flotte 2004]. In addition they do not appear to induce immune responses to the vector sequences or the transduced cell. To date, there are no known diseases associated with rAAV which could limit its use in gene therapy. The AAV genome is a $4.7 \mathrm{~kb}$ single strand DNA which contains only two genes rep and cap (Carter 1992), and short inverted terminal repeats (ITRs). The rep gene encodes proteins involved in replication, while the cap gene encodes the capsid proteins. The ITR sequences are 145 bases long and are the only AAV sequences absolutely required in cis to function as the origin of replication, for packaging into AAV particles, and for efficient integration. The rAAV vectors have been constructed by deleting the rep and cap genes and replacing them with the gene of interest, leaving the ITR as the only viral DNA sequences retained in the rAAV vectors. The rAAV-mediated gene therapies have been investigated in both the canine [Beaty et al., 2002] and murine [Sun et al., 2002; Ghosh et al., 2006; Koeberl et al., 2006] models.

In the canine study Beaty et al. [2002] investigated the effects of a neonatal infusion of 3 GSDIa dogs of Maltase-Beagle crossbreeding with an AAV serotype 2 (AAV2) vector carrying canine G6Pase- $\alpha$ (cG6Pase- $\alpha$ ) under the control of an albumin promoter-enhancer, expected to provide a liver-specific expression profile. The 3 animals each received a different dosage, namely $1.6,7.0$, or $14 \times 10^{11}$ particles of AAV2-cG6Pase- $\alpha$ per dog and they died at 39, 86 and 20 days post-infusion, respectively, showing that survival was not linearly dependent on the viral dose. This strategy resulted in hepatic expression of $10.6 \%$ of wild-type G6Pase- $\alpha$ activity by infusion of $7.0 \times 10^{11}$ particles/dog and $14.9 \%$ of wild-type activity by infusion of both $1.6 \times 10^{11}$ and $14 \times 10^{11}$ particles/dog. Therefore, the activity restored in the liver did not correlate with the dosage of rAAV2 particles administered. All 3 animals were found to be hypoglycemic at death, although it remains unclear if glucose therapy was terminated following infusion. The biochemical profile of the serum was examined in all three infused animals. The fasting glucose levels were normalized for two puppies that received the lower dose of AAV2-

Curr Gene Ther. Author manuscript; available in PMC 2008 September 26. 
cG6Pase- $\alpha$, which suggests $10.6 \%$ of wild type G6Pase- $\alpha$ activity can be sufficient to normalize fasting glucose. However, the correction of cholesterol, triglycerides, and lactate was only achieved in the animal that lived to 86 days of age and only observed after 8 weeks of age. This dog also exhibited an improved liver histology compared to untreated controls. Since this animal had the lowest level of G6Pase- $\alpha$ activity restored in the liver, it suggests that the normalization of the GSD-Ia phenotype is dependent on the length of survival and, again, $10.6 \%$ of wild type G6Pase- $\alpha$ activity might be sufficient. While a promising observation, the number of animals investigated was small and therefore, it is difficult to conclude if the therapy could reliably correct this genetic disorder.

In the first murine study [Sun et al., 2002], neonatal infusion of G6Pase- $\alpha^{-/-}$mice with a rAAV2 carrying murine G6Pase- $\alpha$ (AAV2-mG6Pase- $\alpha$ ) was performed using a recombinant gene driven by a constitutive chicken $\beta$-actin promoter/CMV enhancer expected to be expressed efficiently in most tissues. Immediately following the AAV2-mG6Pase- $\alpha$-infusion, glucose therapy was terminated in the mice, forcing them to depend solely on the recombinant gene expression. However, AAV2-mG6Pase- $\alpha$ alone failed to normalize hypoglycemia or sustain the life of G6Pase- $\alpha^{-/-}$mice because the kinetics of rAAV2-mediated transgene expression was too slow [Thomas et al., 2004]. To address this, a two step regime strategy was examined [Sun et al., 2002] consisting of the use of two different viral vectors - the AAV2-mG6Pase- $\alpha$ and an Ad-mG6Pase- $\alpha$ [Zingone et al., 2000]. In the first step, a neonatal co-infusion of both vectors, $10^{9}$ infectious units (equivalent to $4 \times 10^{13}$ vector particles $/ \mathrm{kg}$ ) of AAV2-mG6Pase$\alpha$ and $4 \times 10^{7}$ PFU of Ad-mG6Pase was implemented. This was followed by a second infusion, at 2 -weeks of age, with a higher dose $\left(5 \times 10^{9}\right.$ infectious units, equivalent to $8 \times 10^{13}$ vector particles $/ \mathrm{kg}$ ) of just AAV2-mG6Pase- $\alpha$. The strategy, conducted on 10 animals, completely prevented premature deaths and corrected the metabolic abnormalities of the murine GSD-Ia disorder for the full 12 months of the study [Sun et al., 2002]. In contrast, untreated G6Pase$\alpha^{-/-}$mice supported only by glucose therapy rarely survived beyond weaning [Lei et al., 1996]. As anticipated, the G6Pase- $\alpha$ transgene was expressed in both the liver and kidney, and resulted in the sustained expression of a complete, functional, G6Pase- $\alpha$ system. Of particular significance was the finding that the Ad/AAV2-mG6Pase- $\alpha$-infused animals grew normally, with only mild glycogen accumulation in the liver and the kidney.

While this two vector, two step therapy appeared promising, this particular regime was not clinically relevant because recombinant Ad-mediated gene transfer is associated with undesirable inflammation and cellular immune responses [Benihoud et al., 1999; Wilson 2001]. Moreover, while AAV2 is not considered pathogenic, and has not been implicated in known human diseases [Tenenbaum et al., 2003; McCarty et al., 2004; Flotte 2004], it does have a number of practical limitations also. For instance, in addition to the delayed onset of gene expression, the vector has low transduction efficiencies [Thomas et al., 2004; Gao et al., 2005]. Moreover, there is a prevailing pre-existing immunity in the general human population to the AAV2 serotype, which limits its value as a clinical gene therapy vector [Gao et al., 2005]. Therefore an improved strategy is needed.

Since the original work a number of other, novel AAV serotypes have been identified and adapted for use [Chao et al., 2000; Gao et al., 2002; Rabinowitz et al., 2002; Grimm and Kay 2003; Choi et al., 2005; Gao et al., 2005]. These new AAV vectors have improved potency, broadened tropism, and the ability to circumvent the pre-existing immunity to AAV2. Of particular value for these vectors has been the development of a transcapsidation method that enables the packaging of rAAV2 genomes within the capsids of these different AAV species [Gao et al., 2002; Rabinowitz et al., 2002]. These advances were exploited in the second [Ghosh et al., 2006] and third [Koeberl et al., 2006] murine GSD-I studies, that used AAV serotypes shown to direct efficient hepatic gene transfer [Rabinowitz et al., 2002; Loiler et al., 2003; Gao et al., 2002; Thomas et al., 2004]. 
In the study of Ghosh et al. [2006] rAAV serotype 1 (rAAV1) [Rabinowitz et al., 2002; Loiler et al., 2003] and rAAV serotype 8 (rAAV8) [Gao et al., 2002; Thomas et al., 2004] were evaluated. These different AAV serotypes display distinct tissue tropism, believed to be related to the distribution of their receptors on target cells. The primary receptors for AAV1 are alpha-2,3-linked, or alpha-2,6-linked, sialic acid which also transduces AAV6 [Wu et al., 2006] while the primary receptor for AAV8 is the $37 / 67-\mathrm{kDa}$ laminin receptor which also plays a role in transduction of AAV2, AAV3, and AAV9 [Akache et al., 2006]. So different efficiencies in transducing the liver and kidney between rAAV1 and rAAV8 might be anticipated, based on the distribution of the receptors on the surfaces of the liver and kidney. In both vectors, the murine G6Pase- $\alpha$ was under the control of a chicken $\beta$-actin promoter driven by a CMV enhancer [Ghosh et al., 2006]. Because the volume of the virus that can be administered to a neonatal mouse is restricted by the size of the mouse, two parallel studies were conducted. One group of mice was infused once neonatally with $5 \times 10^{11}$ particles (equivalent to $2 \times 10^{14}$ vector particles/kg) of AAV1-mG6Pase- $\alpha$ (or AAV8-mG6Pase- $\alpha$ ), while the second group was infused with two doses $-5 \times 10^{11}$ particles (equivalent to $2.5 \times$ $10^{14}$ vector particles/kg) of AAV1-mG6Pase- $\alpha$ (or AAV8-mG6Pase- $\alpha$ ) in the neonatal period and again with $1.5 \times 10^{12}$ particles of AAV1-mG6Pase- $\alpha$ (or AAV8-mG6Pase- $\alpha$ ) when the animals were 1-week old. Again, immediately following AAV1-mG6Pase- $\alpha$ or AAV8mG6Pase- $\alpha$ infusion, glucose therapy was terminated in the mice, forcing them to depend solely on the recombinant gene expression.

Three G6Pase- $\alpha^{-/-}$mice received a single infusion of AAV8-mG6Pase- $\alpha$ and another 3 received the double infusion. In both groups the G6Pase- $\alpha$ transgenes were effectively delivered to the liver and the survival of the mice was markedly improved [Ghosh et al., 2006]. However, there was little or no detectable transgene expression in the kidney with either treatment group. At 6 weeks post-infusion, the doubly AAV8-mG6Pase- $\alpha$-infused mice, who had received the highest recombinant gene dose, had $20.3 \%$ of normal hepatic G6Pase- $\alpha$ activity, but only $0.3 \%$ of normal kidney activity. Since there is strong evidence to suggest that hepatic, as well as renal, G6Pase- $\alpha$ gene expression is required for longer term correction of GSD-Ia [Matern et al., 1999; Sun et al., 2002], the rAAV8-mediated therapy still did not fully address the long term goals and was terminated.

The single AAV1-mG6Pase- $\alpha$-mediated infusion study, conducted on 12 animals, resulted in markedly improved survival of the infused mice [Ghosh et al., 2006]. G6Pase- $\alpha$ activities in the liver and the kidney were $\sim 4 \%$ and $\sim 3 \%$ of normal activity, respectively, and the activities persisted for the duration of the 48 week study. However, 4 of the 7 animals designated for longer term study died prematurely at $12,13,15$, and 30 weeks post-infusion, suggesting that these levels of hepatic and renal G6Pase- $\alpha$ activities are borderline for the survival of the treated G6Pase- $\alpha^{-/-}$mice.

The double infusion study of AAV1-mG6Pase- $\alpha$, conducted on 9 animals, resulted in a sustained level of expression of the G6Pase- $\alpha$ transgene in both the liver and kidney [Ghosh et al., 2006]. The AAV1-mG6Pase- $\alpha$-infused animals grew normally. There were no premature deaths of the infused mice, and no anti-G6Pase- $\alpha$ antibodies detected, even in the doublyinfused G6Pase- $\alpha^{-/-}$mice that were not sacrificed until the end of the full study at 57 weeks. Similarly, in the livers of the doubly infused animals there were no histological abnormalities throughout the 57-week study. Biochemical measurement of microsomes isolated from the treated mice showed sustained restoration of approximately $11 \%$ of the normal liver G6Pase$\alpha$ activity at 57 weeks post-infusion. All infused mice had normal plasma glucose, cholesterol, triglyceride, and uric acid profiles, indicating that glucose homeostasis was being adequately maintained. In the kidneys, biochemical measurements showed that the restoration of approximately $7 \%$ of the normal kidney G6Pase- $\alpha$ activity was sustained for the duration of the study. Pathology analysis showed that the normal kidney histology was maintained over 
most of the study, although increased glycogen accumulation and the development of histological abnormalities including glomerulosclerosis and tubular dilatation, indicative of kidney disease did start to emerge at 57 weeks. Despite this, the serum levels of creatinine, an index of altered renal function [Ruilope et al., 2001], remained within the normal range. Since G6Pase- $\alpha$ is primarily expressed in the kidney cortex [Nordlie and Sukalski 1985; Pan et al., 1998 b], these results suggest that $7 \%$ of wild-type renal G6Pase- $\alpha$ activity, when uniformly expressed throughout the kidney tissues, cannot prevent longer term kidney complications. Clearly correction of the initial metabolic symptoms of GSD-Ia can be attained, but liver correction appears to be easier than kidney correction. This may explain why the current symptomatic dietary therapies for human GSD-Ia patients targeting the control of symptomatic hypoglycemia, result in good glucose homeostasis, but fail to prevent longer term kidney complications.

In the third murine study [Koeberl et al., 2006], conducted on 9 G6Pase- $\alpha^{-/-}$mice of the same strain used in the studies of Ghosh et al. [2006], $1 \times 10^{12}$ particles (equivalent to $2 \times 10^{14}$ vector particles $/ \mathrm{kg}$ ) of a rAAV8 carrying the canine G6Pase- $\alpha$ under the control of the canine G6Pase- $\alpha$ promoter were administrated to 2 -week-old G6Pase- $\alpha^{-/-}$mice. During the 28 -week study, the infused animals grew normally, exhibited normal serum cholesterol and triglyceride profiles, but had only partially normalized blood glucose levels. Hepatic G6Pase- $\alpha$ activity declined from $42 \%$ of wild type activity at 4 -weeks post-infusion to $21 \%$ of wild type activity at 28 weeks, a 50\% decline in only 24 weeks. While the levels of expression obtained were higher than those for the single AAV1 infusion of mouse G6Pase- $\alpha$ described above, the outcome of the two studies were similar. Two of the 9 AAV8-cG6Pase- $\alpha$-infused mice died prematurely. Also consistent with the study of Ghosh et al. [2006], AAV8-cG6Pase- $\alpha-$ mediated gene transfer resulted in little or no renal G6Pase- $\alpha$ expression [Koeberl et al., 2006]. Since liver transplantation corrected metabolic abnormalities seen in GSD-Ia patients, the levels of hepatic G6Pase- $\alpha$ activity appear to correlate, in general, with phenotypic correction. However, hepatic G6Pase- $\alpha$ activity remained high in both studies, $21 \%$ of normal activity at 28 weeks post AAV8-cG6Pase- $\alpha$ infusion [Koeberl et al., 2006] and 11\% of normal activity at 57 weeks post AAV1-mG6Pase- $\alpha$ infusion [Ghosh et al., 2006].

The need for dual, high dose infusions of the rAAV vectors for long term survival of G6Pase$\alpha^{-/-}$mice may reflect, to some degree, the state of the infused vector. Extrachromosomal forms of rAAV are the primary mediators of gene expression in the liver (Nakai et al., 2001) and these will become diluted or lost during the extensive hepatocyte cell division occurring in the rapidly growing neonatal and young mice. This may explain the $50 \%$ decline over 24 weeks in the AAV8-cG6Pase- $\alpha$-mediated hepatic G6Pase- $\alpha$ expression in mice infused at 2 weeks of age [Koeberl et al. 2006]. Such an interpretation is also consistent with the finding of persistent long-term hepatic transgene expression mediated by rAAV8 in mature mice [Conlon et al., 2005; Nakai et al., 2005] and rat [Seppen et al., 2006] where there is a much lower rate of hepatic cell division. But extrachromosomal expression can not explain all of the observed effects, since the AAV1-mG6Pase- $\alpha$-mediated hepatic G6Pase- $\alpha$ expression appeared to persist throughout the duration of the 48- to 57-week study [Ghosh et al. 2006]. Therefore it will be important in future studies to address the other significant differences between the two studies such as the age of the mice receiving gene transfer; the earliest time point analyzed for G6Pase- $\alpha$ expression; the serotype used; and the expression cassettes used in the vectors. In this respect, the differences in the promoters used between the studies may be particularly significant. The canine G6Pase- $\alpha$ in rAAV8 is under the control of nucleotides -1272 to -11 of the 5'-flanking region of the canine G6Pase- $\alpha$ gene. This would seem reasonable given that transient expression assays have shown that the minimal human G6Pase- $\alpha$ promoter is contained within nucleotides -234 to +3 of the 5 '-flanking region [Lin et al., 1977]. However, the sequences that direct tissue-specific G6Pase- $\alpha$ gene expression in vivo have not been characterized in the human or the canine gene and it remains possible the canine G6Pase- $\alpha$ 
promoter used lacked DNA elements necessary for persistent expression. What was demonstrated successfully, however, was that the canine G6Pase- $\alpha$ protein is sufficiently conserved across species that it can couple functionally with the murine G6PT.

The high doses used in both studies [Ghosh et al., 2006; Koeberl et al., 2006] were chosen in an effort to maximize the therapeutic potential because the G6Pase- $\alpha^{-/-}$mice suffer from frequent hypoglycemic seizures [Lei et al., 1996]. However, a dose-response correlation should be performed in the G6Pase- $\alpha^{-/-}$mice to determine if a lower dose of rAAV is equally effective in correcting the GSD-Ia disorder. It has been shown that the rAAV doses used in hemophilia A mice were not predictive of vector efficiency in hemophilia A dogs [Sarkar et al., 2006; Jiang et al., 2006] which are a useful preclinical model of scale-up for the therapeutic outcome in humans. Therefore a careful study of rAAV-mediated gene therapy should also be conducted in the GSD-Ia dog before the current guidelines for human clinical trials are met.

AAV vectors induce little or no innate immunity and the vectors do not contain any viral open reading frames, leaving the transgene product and the virus capsid as the only source of foreign antigens [reviewed in Bessis et al., 2004; Zaiss and Muruve 2005]. A humoral response directed against the G6Pase- $\alpha$ transgene was not observed in the infused G6Pase- $\alpha^{-/-}$mice [Sun et al., 2002; Ghosh et al., 2006] but focal lymphocytic infiltrations in the liver and kidney were present in the AAV8-cG6Pase- $\alpha$-infused mice [Koeberl et al., 2006], suggesting an inflammatory response to the AAV8 capsid. The anti-AAV antibodies can decrease the efficiency of in vivo gene therapy and prevent vector re-administration. In the phase $1 / 2$ gene therapy clinical trials for hemophilia B, it was shown that T cell-mediated immunity to AAV capsid antigen caused destruction of AAV2-transduced hepatocytes [Manno et al., 2006]. Strategies to overcome humoral immunity to the AAV capsids have been reviewed by Zaiss and Muruve [2005] which include AAV capid alterations, alterative serotypes, and immunosuppression during primary exposure. The AAV capsid needed to deliver the therapeutic gene is present only transiently in the transduced cells being gradually degraded and cleared. Therefore, a short-term immunomodulatory regimen that blocks the response to capsid until these sequences are completely cleared from the AAV-transduced cells may permit long-term expression of the transgene.

In summary, the sustained hepatic G6Pase- $\alpha$ transgene expression mediated by rAAV1 and rAAV8 as well as renal G6Pase- $\alpha$ transgene expression mediated by rAAV1 raise the possibility that human GSD-Ia may be amenable to AAV-G6Pase- $\alpha$ gene therapy, although a number of key questions remain to be investigated before clinical trials could be contemplated.

\section{GSD-Ib}

The G6PT defects leading to GSD-Ib are less common than the G6Pase- $\alpha$ defects and represent approximately $20 \%$ of all GSD-I cases [Chen 2001; Chou et al., 2002; Rake et al., 2002; Chou and Mansfield, 2003]. The primary function of G6PT is to translocate G6P from the cytoplasm to the lumen of the ER where it is hydrolyzed to glucose by G6Pase- $\alpha$ (Fig. 2). Both human [Marcolongo et al., 1998; Hiraiwa et al., 1999; Gerin et al., 1999] and mouse [Chen et al., 2003] G6PT are encoded by single copy genes, spanning 5.5-6.5 kb of chromosomal DNA, and composed of 9 exons. In the human, the G6PT gene maps to chromosome 11q23 [Annabi et al., 1998] and in the mouse it maps to chromosome 9.

The human G6PT gene encodes two alternatively spliced transcripts [Marcolongo et al., 1998; Hiraiwa et al., 1999; Gerin et al., 1999]. The primary transcript (G6PT) encodes a 429 amino acid protein, while the variant transcript (vG6PT), which contains an additional 66-bp in exon-7, encodes a 451 amino acid protein. The G6PT transcript is expressed in all tissues examined [Lin et al., 1998], in contrast to the G6Pase- $\alpha$ gene, although tissue specific splicing may occur. For example, the vG6PT transcript is expressed primarily in the brain, heart, and 
skeletal muscle [Lin et al., 2000]. Both G6PT variants function as transporters and can couple with G6Pase- $\alpha$ to form an active G6Pase- $\alpha$ complex [Hiraiwa et al., 1999; Lin et al., 2000]. Both G6PT (Fig. 1) [Pan et al., 1999] and vG6PT [Lin et al., 2000] are hydrophobic, 10 transmembrane domain, ER proteins, with a similar topology. To be functional, the G6PT must embed within the ER membrane in the correct conformation not only to transport G6P, but also couple functionally to the hydrolytic enzyme G6Pase- $\alpha$. Neither of the G6PT proteins can be expressed in a active soluble form, thus protein replacement therapy is not an option for GSD-Ib either.

GSD-Ib has a similar clinical course to GSD-Ia and patients manifest a disturbed glucose homeostasis characterized by fasting hypoglycemia, hepatomegaly, nephromegaly, hyperlipidemia, hyperuricemia, lactic acidemia, and growth retardation. In addition, GSD-Ib patients manifest neutropenia along with myeloid dysfunctions in $\mathrm{Ca}^{2+}$ mobilization, respiratory burst, and chemotaxis [Beaudet et al., 1980; Gitzelmann and Bosshard 1993; Visser et al., 2002; Chou and Mansfield 2003]. Oral and intestinal mucosal ulcerations are common in GSD-Ib, and most patients also suffer from chronic inflammatory bowel disease [Roe $e t$ al., 1986; Visser et al., 2002]. Long-term complications include renal disease and hepatic adenomas that may undergo malignant transformation. GSD-Ib patients receiving liver transplantation have exhibited improved metabolic profiles, confirming the role of hepatic G6PT in glucose homeostasis. However, the consequence transplanted liver on the myeloid dysfunction remains controversial. In two transplant patients, neutropenia was resolved, at least for the first 3 and 4 years after transplantation [Martinez-Olmos et al., 2001; Adachi et al., 2004], but in the other three patients, neutropenia persisted [Lachaux et al., 1993; Matern et al., 1999]. The neutropenia and myeloid dysfunctions manifested by GSD-Ib patients are not obviously related to G6P metabolism in the gluconeogenic tissues of the liver, kidney and small intestine, and point to a potential role of G6PT in bone marrow. Bone marrow transplantation experiments between wild-type and G6PT-deficient mice were conducted to determine if G6PT expression in the bone marrow is linked to myeloid functions [Kim et al., 2006]. The study showed that neutrophils lacking G6PT have intrinsic defects in their respiratory burst, chemotaxis, and $\mathrm{Ca}^{2+}$ mobilization. The study established that while the metabolic dysfunctions are due to the loss of G6PT in the liver, kidney and intestine, the myeloid dysfunctions are due to the loss of G6PT expression in the bone marrows and neutrophils. Therefore, to correct all of the abnormalities associated with GSD-Ib, a functional G6PT must be expressed in multiple tissues.

\section{Gene Therapy for GSD-Ib}

The GSD-Ib disorder has only been described in humans and there are no naturally occurring animal models for the disease. A G6PT-deficient $\left(\mathrm{G} \mathrm{PT}^{-/-}\right)$mouse model of GSD-Ib was

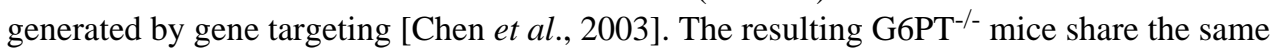
phenotype as human GSD-Ib patients manifesting a disturbed glucose homeostasis as well as

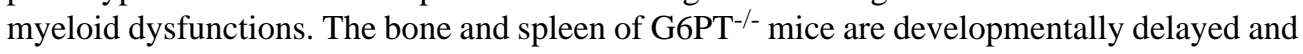
accompanied by marked hypocellularity and elevation of myeloid progenitor cell frequencies in both organs. There is a corresponding dramatic increase in G-CSF levels in GSD-Ib mice which mirrors the findings in human GSD-Ib patients [Chen et al., 2003]. The mouse study also shows that in addition to transient neutropenia, a sustained defect in neutrophil trafficking may underlie the myeloid deficiency in GSD-Ib.

Of the currently available viral vectors, adenovirus [Legrand et al., 2002; Mizuguchi and Hayakawa 2004] and AAV [Carter and Samulski 2000; Tenenbaum et al., 2003; Flotte 2004; McCarty et al., 2004] are two of the most efficient at transducing nondividing cells and both tranduce liver efficiently. In vitro studies had suggested the Ad vectors might also be effective with bone marrow cells [Mitani et al., 1994] and embryonic stem cells [Mitani et al., 1995]. 
More recent results suggest that AAV1 might be effective with primitive murine hematopoietic stem cells [Zhong et al., 2006]. However, there has been no information on the ability of recombinant adenovirus or AAV to deliver a transgene to myeloid tissues in vivo.

Yiu et al. [2006] first evaluated the feasibility of gene replacement therapy for GSD-Ib by infusing an Ad vector carrying human G6PT (Ad-hG6PT) under the control of the constitutive RSV promoter into ${\mathrm{G} 6 \mathrm{PT}^{-/}}^{-}$mice. Because fetal liver is a hematopoietic organ in the first 10 postnatal days [Wolber et al., 2002], two parallel studies were conducted to ensure that AdhG6PT-mediated gene transfer delivered the transgene to gluconeogenic as well as myeloid tissues. One group of mice was infused neonatally with $5 \times 10^{7} \mathrm{PFU}$ of Ad-hG6PT, the second group was infused with $3 \times 10^{8} \mathrm{PFU}$ when the animals reached age 2 weeks. Similar results were obtained. Ad-hG6PT-infusion restored significant levels of G6PT mRNA expression in the liver, bone marrow, and spleen. At 1 and 2 weeks post-Ad-hG6PT infusion, microsomal G6P transport activity in the liver reached $38 \%$ and $29 \%$, respectively of normal hepatic activities and the GSD-Ib mice receiving the recombinant virus exhibit improved growth; normalized serum profiles of glucose, cholesterol, triglyceride, uric acid and lactate; reduced hepatic glycogen storage; and improved hepatomegaly. These changes were all consistent with the reconstitution of a functional G6Pase system in the gluconeogenic tissues. In addition, the Ad-mediated gene transfer also improved neutropenia; normalized serum G-CSF levels; improved bone and spleen development; lead to increased cellularity of the bone and spleen; and normalized myeloid progenitor cell frequencies in both tissues. These findings are consistent with the reconstitution of G6PT activity in the myeloid cells, demonstrating that recombinant adenovirus can deliver a transgene to the bone marrow in vivo.

In contrast to the G6PT reconstitution within the liver, bone marrow, and spleen, effective adenovirus-mediated G6PT transduction of the kidney did not occur, and the typical GSD-Ib characteristics of kidney enlargement associated with abnormal glycogen deposition, continued to develop [Yiu et al., 2006]. Therefore, correction of the full phenotype of GSD$\mathrm{Ib}$ will require co-transfection of an adenoviral vector carrying G6PT with a second G6PT carrying vector capable of transducing the kidney, or the use of a single vector with a liver, kidney, bone marrow and spleen transduction potential.

The Ad vector used by Yiu et al. [2006] is further limited by the short-term expression of the transgene [Benihoud et al., 1999; Wilson 2001] and effective gene therapy requires sustained expression of the transgene. Helper-dependent adenoviral vectors deleting most or all of the viral protein encoding sequence [Alba et al., 2005; Jozkowicz and Dulak 2005; Palmer and Ng 2005; Bangari and Mittal 2006] which are significantly less toxic may be more attractive in the future. The AAV vector, which has been shown to correct the GSD-Ia disorder, is also attractive. Further investigation should identify a more comprehensive gene therapy vector that will achieve long-term correction of metabolic and myeloid dysfunctions in GSD-Ib or that a transgene can be repeatedly administrated in the absence of adverse immune responses. In summary, the effective use of gene therapy to correct metabolic imbalances and myeloid dysfunctions in GSD-Ib mice holds promise for the future of gene therapy in humans.

\section{Acknowledgement}

This research was supported in part by the Intramural Research Program of the NICHD, NIH

\section{References}

Adachi M, Shinkai M, Ohhama Y, Tachibana K, Kuratsuji T, Saji H, Maruya E. Improved neutrophil function in a glycogen storage disease type $1 \mathrm{~b}$ patient after liver transplantation. Eur. J. Pediatr 2004;163:202-206. [PubMed: 14872340] 
Akache B, Grimm D, Pandey K, Yant SR, Xu H, Kay MA. The 37/67-kilodalton laminin receptor is a receptor for adeno-associated virus serotypes 8, 2, 3, and 9. J. Virol 2006;80:9831-9836. [PubMed: 16973587]

Alba R, Bosch A, Chillon M. Gutless adenovirus: last-generation adenovirus for gene therapy. Gene Ther 2005;12(Suppl 1):S18-S27. [PubMed: 16231052]

Annabi B, Hiraiwa H, Mansfield BC, Lei K-J, Ubagai T, Polymeropoulos MH, Moses SW, Parvari R, Hershkovitz E, Mandel H, Frydman M, Chou JY. The gene for glycogen storage disease type 1b maps to chromosome 11q23. Am. J. Hum. Genet 1998;62:400-405. [PubMed: 9463334]

Bangari DS, Mittal SK. Current strategies and future directions for eluding adenovirual vector. Curr. Gene Ther 2006;6:215-226. [PubMed: 16611043]

Beaty RM, Jackson M, Peterson D, Bird A, Brown T, Benjamin DK Jr. Juopperi T, Kishnani P, Boney A, Chen YT, Koeberl DD. Delivery of glucose-6-phosphatase in a canine model for glycogen storage disease, type Ia, with adeno-associated virus (AAV) vectors. Gene Ther 2002;9:1015-1022. [PubMed: 12101432]

Beaudet AL, Anderson DC, Michels VV, Arion WJ, Lange AJ. Neutropenia and impaired neutrophil migration in type 1B glycogen storage disease. J. Pediatr 1980;97:906-910. [PubMed: 6255119]

Benihoud K, Yeh P, Perricaudet M. Adenovirus vectors for gene delivery. Curr. Opin. Biotechnol 1999;10:440-447. [PubMed: 10508634]

Bessis N, GarciaCozar FJ, Boissier MC. Immune responses to gene therapy vectors: influence on vector function and effector mechanisms. Gene Ther 2004;11(Suppl 1):S10-S17. [PubMed: 15454952]

Calderwood S, Kilpatrick L, Douglas SD, Freedman M, Smith-Whitley K, Rolland M, Kurtzberg J. Recombinant human granulocyte colony-stimulating factor therapy for patients with neutropenia and/or neutrophil dysfunction secondary to glycogen storage disease type 1b. Blood 2001;97:376382. [PubMed: 11154211]

Carter BJ. Adeno-associated virus vectors. Curr. Opin. Biotechnol 1992;3:533-539. [PubMed: 1369403]

Carter PJ, Samulski RJ. Adeno-associated viral vectors as gene delivery vehicles. Int. J. Mol. Med 2000;6:17-27. [PubMed: 10851261]

Chao H, Liu Y, Rabinowitz J, Li C, Samulski RJ, Walsh CE. Several log increase in therapeutic transgene delivery by distinct adeno-associated viral serotype vectors. Mol. Ther 2000;2:619-623. [PubMed: 11124063]

Chen L-Y, Shieh J-J, Lin B, Pan C-J, Gao J-L, Murphy PM, Roe TF, Moses S, Ward JM, Westphal H, et al. Impaired glucose homeostasis, neutrophil trafficking and function in mice lacking the glucose-6phosphate transporter. Hum. Mol. Genet 2003;12:2547-2558. [PubMed: 12925567]

Chen, Y-T. Glycogen storage diseases. In: Scriver, CR.; Beaudet, AL.; Sly, WS.; Valle, D.; Childs, B.; Kinzler, KW.; Vogelstein, B., editors. The Metabolic and Molecular Bases of Inherited Disease. 8th Ed.. McGraw-Hill Inc.; New York: 2001. p. 1521-1551.

Chen YT, Cornblath M, Sidbury JB. Cornstarch therapy in type I glycogen storage disease. N. Engl. J. Med 1984;310:171-175. [PubMed: 6581385]

Chen YT, Scheinman JI. Hyperglycaemia associated with lactic acidemia in a renal allograft recipient with type I glycogen storage disease. J. Inherit. Metab. Dis 1991;14:80-86. [PubMed: 1861463]

Choi VW, McCarty DM, Samulski RJ. AAV hybrid serotypes: improved vectors for gene delivery. Curr. Gene Ther 2005;5:299-310. [PubMed: 15975007]

Chou JY, Mansfield BC. Molecular genetics of type 1 glycogen storage diseases. Trend Endocrinol. Metab 1999;10:104-113.

Chou, JY.; Mansfield, BC. Glucose-6-phosphate transporter: the key to glycogen storage disease type Ib. In: Broer, S.; Wagner, CA., editors. Membrane Transporter Diseases. Kluwe Academic/Plenum Publishers; New York: 2003. p. 191-205.

Chou JY, Matern D, Mansfield BC, Chen Y-T. Type I glycogen storage diseases: disorders of the glucose-6-phosphatase complex. Curr. Mol. Med 2002;2:121-143. [PubMed: 11949931]

Conlon TJ, Cossette T, Erger K, Choi YK, Clarke T, Scott-Jorgensen M, Song S, Campbell-Thompson M, Crawford J, Flotte TR. Efficient hepatic delivery and expression from a recombinant adenoassociated virus 8 pseudotyped $\alpha 1$-antitrypsin vector. Mol. Ther 2005;12:867-875. [PubMed: 16085464] 
Emmett M, Narins RG. Renal tranplantation in type 1 glycogenosis: failure to improve glucose metabolism. JAMA 1978;239:1642-1644. [PubMed: 204806]

Flotte TR. Gene therapy progress and prospects: recombinant adeno-associated virus (rAAV) vectors. Gene Ther 2004;11:805-810. [PubMed: 15042119]

Gao GP, Alvira MR, Wang L, Calcedo R, Johnston J, Wilson JM. Novel adeno-associated viruses from rhesus monkeys as vectors for human gene therapy. Proc. Natl. Acad. Sci. USA 2002;99:1185411859. [PubMed: 12192090]

Gao GP, Vandenberghe LH, Wilson JM. New recombinant serotypes of AAV vectors. Curr. Gene Ther 2005;5:285-297. [PubMed: 15975006]

Gerin I, Veiga-da-Cunha M, Noel G, Van Schaftingen E. Structure of the gene mutated in glycogen storage disease type Ib. Gene 1999;227:189-195. [PubMed: 10023055]

Ghosh A, Allamarvdasht M, Pan C-J, Sun M-S, Mansfield BC, Byrne BJ, Chou JY. Long-term correction of murine glycogen storage disease type Ia by recombinant adeno-associated virus-1-mediated gene transfer. Gene Ther 2006;13:321-329. [PubMed: 16195703]

Ghosh A, Shieh J-J, Pan C-J, Chou JY. Histidine-167 is the phosphate acceptor in glucose-6-phosphatase$\beta$ forming a phosphohistidine-enzyme intermediate during catalysis. J. Biol. Chem 2004;279:12479_ 12483. [PubMed: 14718531]

Ghosh A, Shieh J-J, Pan C-J, Sun M-S, Chou JY. The catalytic center of glucose-6-phosphatase: His ${ }^{176}$ is the nucleophile forming the phosphohistidine-enzyme intermediate during catalysis. J. Biol. Chem 2002;277:32837-32842. [PubMed: 12093795]

Gitzelmann R, Bosshard NU. Defective neutrophil and monocyte functions in glycogen storage disease type 1b: a literature review. Eur. J. Pediatr 1993;152:S33-S38. [PubMed: 8391445]

Greene HL, Slonim AE, O’Neill JA Jr. Burr IM. Continuous nocturnal intragastric feeding for management of type 1 glycogen-storage disease. N. Engl. J. Med 1976;294:423-425. [PubMed: 813144]

Grimm D, Kay MA. From virus evolution to vector revolution: use of naturally occurring serotypes of adeno-associated virus (AAV) as novel vectors for human gene therapy. Curr. Gene Ther 2003;3:281-304. [PubMed: 12871018]

Gossmann J, Scheuermann EH, Frilling A, Geiger H, Dietrich CF. Multiple adenomas and hepatocellular carcinoma in a renal transplant patient with glycogen storage disease type 1a (von Gierke disease). Transplantation 2001;72:343-344. [PubMed: 11477366]

Guionie O, Clottes E, Stafford K, Burchell A. Identification and characterization of a new human glucose-6-phosphatase isoform. FEBS Lett 2003;551:159-164. [PubMed: 12965222]

Hiraiwa H, Pan C-J, Lin B, Moses SW, Chou JY. Inactivation of the glucose-6-phosphate transporter causes glycogen storage disease type 1b. J. Biol. Chem 1999;274:5532-5536. [PubMed: 10026167]

Jiang H, Lillicrap D, Patarroyo-White S, Liu T, Qian X, Scallan CD, Powell S, Keller T, McMurray M, Labelle A, Nagy D, Vargas JA, Zhou S, Couto LB, Pierce GF. Multiyear therapeutic benefit of AAV serotypes 2, 6, and 8 delivering factor VIII to hemophilia A mice and dogs. Blood 2006;108:107115. [PubMed: 16522813]

Jozkowicz A, Dulak J. Help-dependent adenoviral vectors in experimental gene therapy. Acta Biochem. Pol 2005;52:589-599.

Kim SY, Nguyen AD, Gao J-L, Murphy PM, Mansfield BC, Chou JY. Bone-marrow derived cells require a functional glucose-6-phosphate transporter for normal myeloid functions. J. Biol. Chem 2006;281:28794-28801. [PubMed: 16891306]

Kishnani PS, Bao Y, Wu J-Y, Brix AE, Lin J-L, Chen Y-T. Isolation and nucleotide sequence of canine glucose-6-phosphatase mRNA: identification of mutation in puppies with glycogen storage disease type 1a. Biochem. Mol. Med 1997;61:168-177. [PubMed: 9259982]

Kishnani PS, Faulkner E, VanCamp S, Jackson M, Brown T, Boney A, Koeberl D, Chen YT. Canine model and genomic structural organization of glycogen storage disease type Ia (GSD Ia). Vet. Pathol 2001;38:83-91. [PubMed: 11199168]

Koeberl DD, Sun BD, Damodaran TV, Brown T, Millington DS, Benjamin DK Jr. Bird A, Schneider A, Hillman S, Jackson M, Beaty RM, Chen YT. Early, sustained efficacy of adeno-associated virus vector-mediated gene therapy in glycogen storage disease type Ia. Gene Ther 2006;13:1281-1289. [PubMed: 16672983] 
Labrune P. Glycogen storage disease type I: indications for liver and/or kidney transplantation. Eur. J. Pediatr 2002;161(Suppl 1):S53-S55. [PubMed: 12373572]

Lachaux A, Boillot O, Stamm D, Canterino I, Dumontet C, Regnier F, Floret D, Hermier M. Treatment with lenograstim (glycosylated recombinant human granulocyte colony-stimulating factor) and orthotopic liver transplantation for glycogen storage disease type Ib. J. Pediatr 1993;123:1005-1008. [PubMed: 7693904]

Legrand V, Leissner P, Winter A, Mehtali M, Lusky M. Transductional targeting with recombinant adenovirus vectors. Curr. Gene Ther 2002;2:323-339. [PubMed: 12189719]

Lei K-J, Chen H, Pan C-J, Ward JM, Mosinger B, Lee EJ, Westphal H, Chou JY. Glucose-6-phosphatase dependent substrate transport in the glycogen storage disease type 1a mouse. Nat. Genet 1996;13:203-209. [PubMed: 8640227]

Lei K-J, Pan C-J, Shelly LL, Liu J-L, Chou JY. Identification of mutations in the gene for glucose-6phosphatase, the enzyme deficient in glycogen storage disease type 1a. J. Clin. Invest 1994;93:19941999. [PubMed: 8182131]

Lei K-J, Shelly LL, Pan C-J, Sidbury JB, Chou JY. Mutations in the glucose-6-phosphatase gene that cause glycogen storage disease type 1a. Science 1993;262:580-583. [PubMed: 8211187]

Lin B, Annabi B, Hiraiwa H, Pan C-J, Chou JY. Cloning and characterization of cDNAs encoding a candidate glycogen storage disease type $1 \mathrm{~b}$ protein in rodents. J. Biol. Chem 1998;273:31656-31670. [PubMed: 9822626]

Lin B, Morris DW, Chou JY. The role of HNF1 $\alpha$, HNF3 $\gamma$ and cyclic AMP in glucose-6-phosphatase gene activation. Biochemistry 1997;36:14096-14106. [PubMed: 9369482]

Lin B, Pan C-J, Chou JY. Human variant glucose-6-phosphate transporter is active in microsomal transport. Hum. Genet 2000;107:526-529. [PubMed: 11140953]

Loiler SA, Conlon TJ, Song S, Tang Q, Warrington KH, Agarwal A, Kapturczak M, Li C, Ricordi C, Atkinson MA, Muzyczka N, Flotte TR. Targeting recombinant adeno-associated virus vectors to enhance gene transfer to pancreatic islets and liver. Gene Ther 2003;10:1551-1558. [PubMed: 12907946]

Manno CS, Pierce GF, Arruda VR, Glader B, Ragni M, Rasko JJ, Ozelo MC, Hoots K, Blatt P, Konkle B, Dake M, Kaye R, Razavi M, Zajko A, Zehnder J, Rustagi PK, Nakai H, Chew A, Leonard D, Wright JF, Lessard RR, Sommer JM, Tigges M, Sabatino D, Luk A, Jiang H, Mingozzi F, Couto L, Ertl HC, High KA, Kay MA. Successful transduction of liver in hemophilia by AAV-Factor IX and limitations imposed by the host immune response. Nat. Med 2006;12:342-347. [PubMed: 16474400]

Marcolongo P, Barone V, Priori G, Pirola B, Giglio S, Biasucci G, Zammarchi E, Parenti G, Burchell A, Benedetti A, Sorrentino V. Structure and mutation analysis of the glycogen storage disease type $1 \mathrm{~b}$ gene. FEBS Lett 1998;436:247-250. [PubMed: 9781688]

Martinez-Olmos MA, Lopez-Sanroman A, Martin-Vaquero P, Molina-Perez E, Barcena R, Vicente E, Candela A, Pallardo-Sanchez LF. Liver transplantation for type Ib glycogenosis with reversal of cyclic neutropenia. Clin. Nutr 2001;20:375-377. [PubMed: 11478837]

Matern D, Starzl TE, Arnaout W, Barnard J, Bynon JS, Dhawan A, Emond J, Haagsma EB, Hug G, Lachaux A, Smit GP, Chen YT. Liver transplantation for glycogen storage disease types I, III, and IV. Eur. J. Pediatr 1999;158:S43-S48. [PubMed: 10603098]

McCarty DM, Young SM Jr. Samulski RJ. Integration of adeno-associated virus (AAV) and recombinant AAV vectors. Annu. Rev. Genet 2004;38:819-845. [PubMed: 15568995]

Mitani K, Graham FL, Caskey CT. Transduction of human bone marrow by adenoviral vector. Hum. Gene Ther 1994;5:941-948. [PubMed: 7948143]

Mitani K, Wakamiya M, Hasty P, Graham FL, Bradley A, Caskey CT. Gene targeting in mouse embryonic stem cells with an adenoviral vector. Somat. Cell Mol. Genet 1995;21:221-231. [PubMed: 8525428]

Mizuguchi H, Hayakawa T. Targeted adenovirus vectors. Hum. Gene Ther 2004;15:1034-1044. [PubMed: 15610604]

Nakai H, Yant SR, Storm TA, Fuess S, Meuse L, Kay MA. Extrachromosomal recombinant adenoassociated virus vector genomes are primarily responsible for stable liver transduction in vivo. J. Virol 2001;75:6969-6976. [PubMed: 11435577]

Nakai H, Fuess S, Storm TA, Muramatsu S, Nara Y, Kay MA. Unrestricted hepatocyte transduction with adeno-associated virus serotype 8 vectors in mice. J. Virol 2005;79:214-224. [PubMed: 15596817] 
Nordlie, RC.; Sukalski, KA. Multifunctional glucose-6-phosphatase: a critical review. In: Martonosi, AN., editor. The Enzymes of Biological Membranes. 2nd Ed.. Plenum Press; New York: 1985. p. 349-398.

Palmer DJ, Ng P. Helper-dependent adenoviral vectors for gene therapy. Hum. Gene Ther 2005;16:116. [PubMed: 15703484]

Pan C-J, Lei K-J, Annabi B, Hemrika W, Chou JY. Transmembrane topology of glucose-6-phosphatase. J. Biol. Chem 1998a;273:6144-6148. [PubMed: 9497333]

Pan C-J, Lei K-J, Chen H, Ward JM, Chou JY. Ontogeny of the murine glucose-6-phosphatase system. Arch. Biochem. Biophys 1998b;358:17-24. [PubMed: 9750160]

Pan C-J, Lei K-J, Chou JY. Asparagine-linked oligosaccharides are localized to a luminal hydrophilic loop in human glucose-6-phosphatase. J. Biol. Chem 1998c;273:21658-21662. [PubMed: 9705299]

Pan C-J, Lin B, Chou JY. Transmembrane topology of human glucose-6-phosphate transporter. J. Biol. Chem 1999;274:3865-13869. [PubMed: 9920942]

Rabinowitz JE, Rolling F, Li C, Conrath H, Xiao W, Xiao X, Samulski RJ. Cross-packaging of a single adeno-associated virus (AAV) type 2 vector genome into multiple AAV serotypes enables transduction with broad specificity. J. Virol 2002;76:791-801. [PubMed: 11752169]

Rake JP, Visser G, Labrune P, Leonard JV, Ullrich K, Smit GP. Glycogen storage disease type I: diagnosis, management, clinical course and outcome. Results of the European Study on Glycogen Storage Disease Type I (ESGSD I). Eur. J. Pediatr 2002;161(Suppl 1):S20-S34. [PubMed: 12373567]

Roe TF, Coates TD, Thomas DW, Miller JH, Gilsanz V. Brief report: treatment of chronic inflammatory bowel disease in glycogen storage disease type Ib with colony-stimulating factors. N. Engl. J. Med 1992;326:1666-1669. [PubMed: 1375344]

Roe TF, Thomas DW, Gilsanz V, Isaacs H, Atkinson JB. Inflammatory bowel disease in glycogen storage disease type Ib. J. Pediatr 1986;109:55-59. [PubMed: 3459848]

Ruilope LM, van Veldhuisen DJ, Ritz E, Luscher TF. Renal function: the Cinderella of cardiovascular risk profile. J. Am. Coll. Cardiol 2001;38:1782-1787. [PubMed: 11738274]

Schroten H, Roesler J, Breidenbach T, Wendel U, Elsner J, Schweitzer S, Zeidler C, Burdach S, LohmannMatthes ML, Wahn V, Welte K. Granulocyte and granulocyte-macrophage colony-stimulating factors for treatment of neutropenia in glycogen storage disease type Ib. J. Pediatr 1991;119:748754. [PubMed: 1719175]

Sarkar R, Mucci M, Addya S, Tetreault R, Bellinger DA, Nichols TC, Kazazian HH Jr. Long-term efficacy of adeno-associated virus serotypes 8 and 9 in hemophilia a dogs and mice. Hum. Gene Ther 2006;17:427-439. [PubMed: 16610930]

Seppen J, Bakker C, de Jong B, Kunne C, van den Oever K, Vandenberghe K, de Waart R, Twisk J, Bosma P. Adeno-associated virus vector serotypes mediate sustained correction of bilirubin UDP glucuronosyltransferase deficiency in rats. Mol. Ther 2006;13:1085-1092. [PubMed: 16581301]

Shelly LL, Lei K-J, Pan C-J, Sakata SF, Ruppert S, Schutz G, Chou JY. Isolation of the gene for murine glucose-6-phosphatase, the enzyme deficient in glycogen storage disease type 1a. J. Biol. Chem 1993;268:21482-21485. [PubMed: 8407995]

Shieh J-J, Pan C-J, Mansfield BC, Chou JY. Glucose-6-phosphate hydrolase, widely expressed outside the liver, can explain age-dependent resolution of hypoglycemia in glycogen storage disease type Ia. J. Biol. Chem 2003;278:47098-47103. [PubMed: 13129915]

Sun M-S, Pan C-J, Shieh J-J, Ghosh A, Chen L-Y, Mansfield BC, Ward JM, Byrne BJ, Chou JY. Sustained hepatic and renal glucose-6-phosphatase expression corrects glycogen storage disease type Ia in mice. Hum. Mol. Genet 2002;11:2155-2164. [PubMed: 12189168]

Tenenbaum L, Lehtonen E, Monahan PE. Evaluation of risks related to the use of adeno-associated virusbased vectors. Curr. Gene Ther 2003;3:545-565. [PubMed: 14683451]

Thomas CE, Storm TA, Huang Z, Kay MA. Rapid uncoating of vector genomes is the key to efficient liver transduction with pseudotyped adeno-associated virus vectors. J. Virol 2004;78:3110-3122. [PubMed: 14990730]

Visser G, Rake JP, Fernandes J, Labrune P, Leonard JV, Moses S, Ullrich K, Smit GP. Neutropenia, neutrophil dysfunction, and inflammatory bowel disease in glycogen storage disease type Ib: results 
of the European Study on Glycogen Storage Disease type I. J. Pediatr 2000;137:187-191. [PubMed: 10931410]

Visser G, Rake JP, Labrune P, Leonard JV, Moses S, Ullrich K, Wendel U, Groenier KH, Smit GP. Granulocyte colony-stimulating factor in glycogen storage disease type $1 \mathrm{~b}$. Results of the European Study on Glycogen Storage Disease Type 1. Eur. J. Pediatr 2002;161(Suppl 1):S83-S87. [PubMed: 12373578]

Wilson JM. Adenovirus-mediated gene transfer to liver. Adv. Drug Deliv. Rev 2001;46:205-209. [PubMed: 11259841]

Wolber FM, Leonard E, Michael S, Orschell-Traycoff CM, Yoder MC, Srour EF. Roles of spleen and liver in development of the murine hematopoietic system. Exp. Hematol 2002;30:1010-1019. [PubMed: 12225792]

Wu Z, Miller E, Agbandje-McKenna M, Samulski R. Alpha2,3 and alpha2,6 N-linked sialic acids facilitate efficient binding and transduction by adeno-associated virus types 1 and 6 . J. Virol 2006;80:9093-9103. [PubMed: 16940521]

Yiu WH, Pan C-J, Allamarvdasht A, Kim SY, Chou JY. Glucose-6-phosphate transporter gene therapy corrects metabolic and myeloid abnormalities in glycogen storage disease type Ib mice. Gene Ther. 2006in press

Zaiss AK, Muruve DA. Immune responses to adeno-associated virus vectors. Curr. Gene Ther 2005;5:323-331. [PubMed: 15975009]

Zhong L, Li W, Li Y, Zhao W, Wu J, Li B, Maina N, Bischof D, Qing K, Weigel-Kelley KA, Zolotukhin I, Warrington KH Jr. Li X, Slayton WB, Yoder MC, Srivastava A. Evaluation of primitive murine hematopoietic stem and progenitor cell transduction in vitro and in vivo by recombinant adenoassociated virus vector serotypes 1 through 5. Hum. Gene Ther 2006;17:321-333. [PubMed: 16544981]

Zingone A, Hiraiwa H, Pan C-J, Lin B, Chen H, Ward JM, Chou JY. Correction of glycogen storage disease type 1a in a mouse model by gene therapy. J. Biol. Chem 2000;275:828-832. [PubMed: 10625614] 


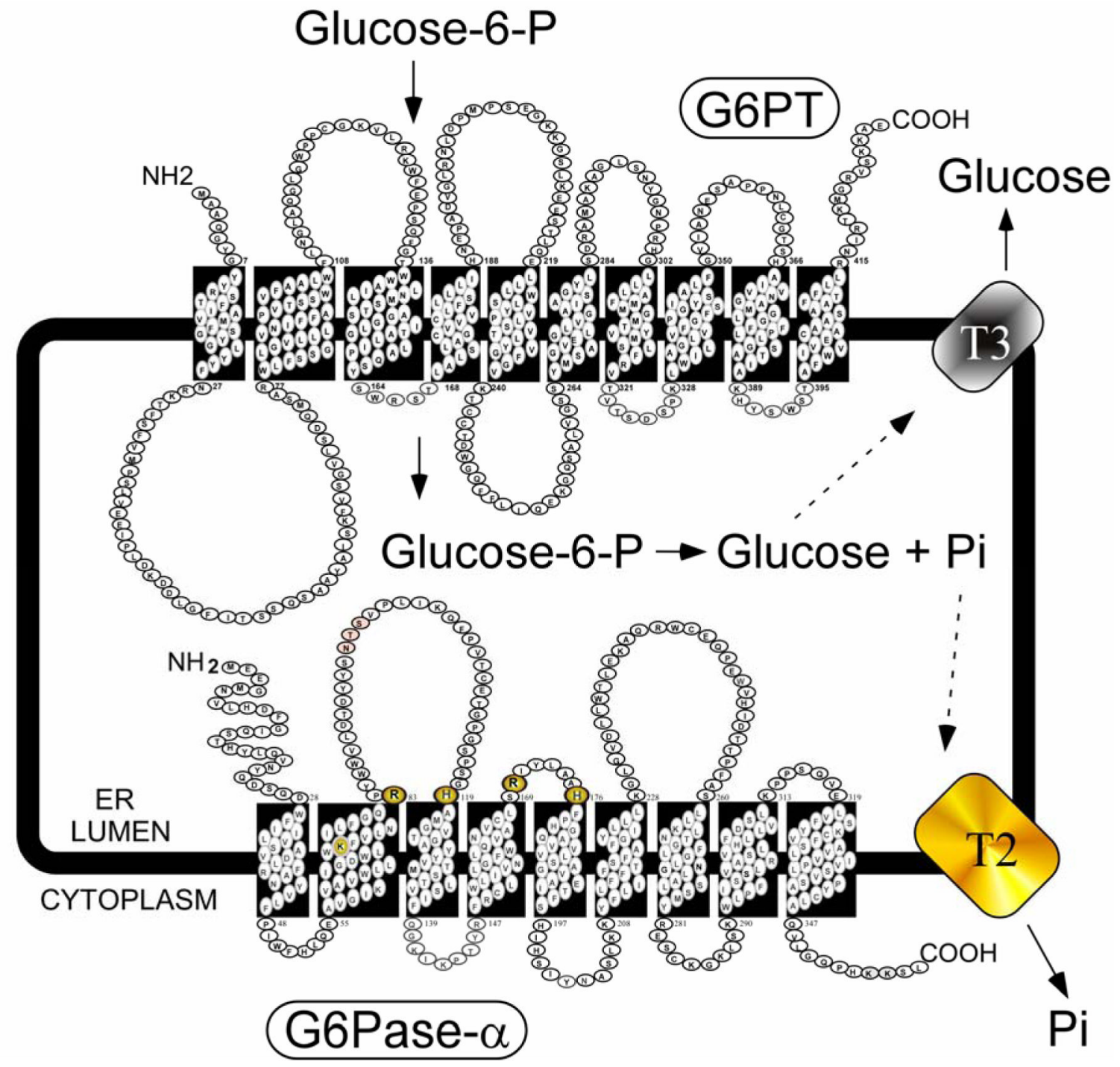

Fig. (1).

The G6Pase- $\alpha$ system, an enzyme complex essential for glucose homeostasis. The components, G6Pase- $\alpha$, G6PT, a putative phosphate transporter (T2), and a putative glucose transporter (T3), are shown anchored in the membrane of the ER in contact with both the cytoplasm and ER lumen. The spatial representation is illustrative only; the proteins must couple functionally and probably exist as a multi-protein cluster. Amino acids participating in G6Pase- $\alpha$ catalysis are highlighted. 


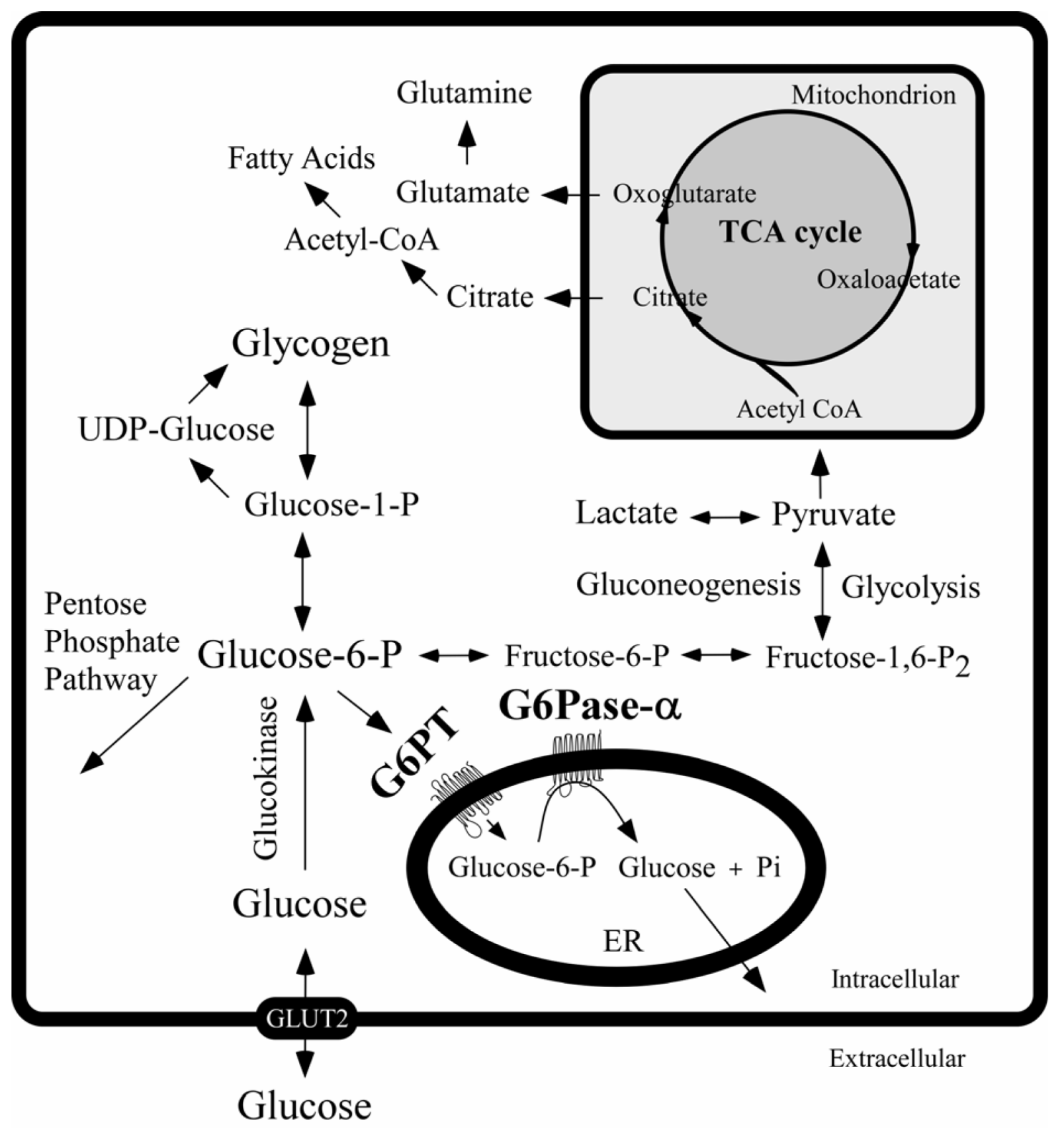

Fig. (2).

The primary anabolic and catabolic pathways of G6P in the liver. The G6Pase- $\alpha$ and G6PT components of the G6Pase- $\alpha$ system are shown embedded within the membrane of the ER. The GLUT2 transporter, responsible for the transport of glucose in and out of the cell, is shown embedded in the plasma membrane. 